\title{
Air pollution of PM10 with radionuclide Cs-137 in Kuwait City, Kuwait
}

\author{
H. Tang ${ }^{1}$, D. Al-Ajmi ${ }^{1} \&$ X. Shen ${ }^{2}$ \\ ${ }^{1}$ Kuwait Institute for Scientific Research, CTBTO \\ ${ }^{2}$ International Monitoring System Division, CTBTO
}

\begin{abstract}
Kuwait City is surrounded by deserts. PM10 is a problem for this city. Statistical studies show that the percentage of violations of the Kuwait government's PM10 standard is high. Cs-137 is a man-made radionuclide produced through nuclear fission. It has very high fission yield, and has a 30.1 years' half-life. From a non-radiological hazards point of view, no potential health effects are known for Cesium. However, large oral doses of the material may cause gastrointestinal disturbances. A large amount of Cs-137 was released into the atmosphere from nuclear tests in early 1950's and 1960's, and from nuclear accidents in the past. The International Commission on Radiological Protection has set up exposure standards for many radionuclide elements.

In cooperation with the Centre of Monitoring Research, USA and the International Monitoring System Division, the Preparatory Commission for the Comprehensive Nuclear-test-ban Treaty Organization, Kuwait Institute for Scientific Research has operated a radionuclide monitoring station in Kuwait City for many years. It has been discovered that Kuwait City has the highest Cs-137 activity concentrations and largest range of concentrations among the CTBTO monitoring stations from 1995 to 1999. This study found from April 2004 to February 2005, the average concentration of Cs-137 in Kuwait City was about the same level of the average concentration from 1995 to 1999 although the monthly average of Cs-137 concentrations had changed. This paper will detail the measurement results, and discuss the health effects.
\end{abstract}

Keywords: radionuclide, Cs-137, health effect, particle, PM10.

\section{Introduction}

There is radiation all around us and we cannot eliminate radiation from our environment. Radioactive materials that decay spontaneously produce ionizing 
radiation, which has sufficient energy to strip away electrons from atoms or to break some chemical bonds. Any living tissue in the human body can be damaged by ionizing radiation. The most common forms of ionizing radiation are alpha and beta particles, or gamma and $\mathrm{x}$-rays. These radiations are from consumer products, security devices, foods, food containers, medical procedures, naturally occurring processes, nuclear test, nuclear power plant emissions etc.

In the atmosphere, one of the radiation sources is particulate phase. The particulate phase can be divided into two major groups according to sizes: corse particles PM10 and fine particles PM2.5.

Radiation effects human health not only directly from a source beaming out and striking the exterior of a body, but also from particles becoming lodged inside the body and exposing internal organs as the radionuclides decay. There are three main routs of exposure to radiation: inhalation, ingestion and direct exposure.

There are many natural radionuclides such as $\mathrm{K}-40$, Be-7, Pb-212, Ac-228, Bi-212, Tl-208 etc. For example, K-40 can be found from Banana. Radon is always in the air that man breathes. Indoor concentrations of Radon are typically $2-10$ times those in outdoor air.

Cs-137 is a man-made radionuclide product through nuclear fission. It has very high fission yield, and has a 30.1 years' half-life. From non-radiological hazards point of view, no potential health effects are known for Cesium. However, large oral doses of the material may cause gastrointestinal disturbances. A large amount of Cs-137 was released into the atmosphere from nuclear tests in early 1950's and 1960's [1-4] and from nuclear accidents in the past. International Commission on Radiological Protection has set up exposure standards for many radionuclide elements.

Cooperated with Centre of Monitoring Research, USA and International Monitoring System Division, Preparatory Commission for the Comprehensive Nuclear-test-ban Treaty Organization (CTBTO), Kuwait Institute for Scientific Research (KISR) has operated a radionuclide monitoring station in Kuwait City for many years. It is well known that Kuwait City is surrounded by deserts, and PM10 is a problem for this city. Statistic studies show that the percentage of violation of Kuwait government PM10 standard is high. Unfortunately it has been further discovered that Kuwait had the highest Cs-137 activity concentrations and largest range of concentrations among the CTBTO radionuclide monitoring stations in the world from 1995 to 1999 [5]. Our study found that from April 2004 to March 2005, the average concentration of Cs-137 in Kuwait was still about the same level as from 1995 to 1999 although the monthly average concentrations were changed. This paper will detail the measurement results, and discuss the health effects.

\section{Radionuclide measurement}

The Comprehensive Nuclear-Test-Ban Treaty (CTBT) establishes the International Monitoring System (IMS) to ensure verification of compliance with the treaty. Prior to entry into force of the Treaty, the IMS is supervised and 
coordinated by the Provisional Technical Secretariat (PTS) and has been designed to provide, on a global scale, monitoring facilities capable of the detection and locating of nuclear explosions. For monitoring atmospheric radionuclides, a global network of radionuclide monitoring stations and radionuclide laboratories is established as part of the IMS. Kuwait has one radionuclide monitoring station. The station is operated by Kuwait Institute for Scientific Research (KISR). A Radionuclide Aerosol Sampler/Analyzer (RASA) [6] (Veridian System Division USA) is installed in the station.

The RASA samples and measures trace quantities of radionuclides in large atmospheric samples (PM10) and report the results to the central data center of CTBT. The RASA system equipment contains a gamma radiation detection system used to monitor the atmosphere for evidence of radionuclide activities. It also includes three mechanical subsystems consisting of a supply mechanism, a segmented sample head, and a multi-function T-bracket. The PM10 particles are collected for 24 hours, decayed for 24 hours, and measured for another 24 hours. The sampling rates are around $600 \mathrm{~m}^{3} /$ hour.

\section{Results and discussions}

Many radionuclide elements such as Be-7, K-40, Pb-212, TL-208, Ac-228, Cs137 etc. have been detected in Kuwait. But Cs-137 is especially interested since it is the key anthropogenic radionuclide indicative of nuclear debris. Due to Cs137 has a half-life of 30.17 years, amounts of this radionuclide releases are still present in the soil and atmosphere as a result of past nuclear tests and reactor releases.

Figure 1 shows the Cs-137 concentrations detected from April 2004 to February 2005. There were 131 days when the Cs-137 was detected. The highest concentration was $270.70 \mu \mathrm{Bq} / \mathrm{m}^{3}$ (May 24-25, 2004) and the lowest was 1.40 $\mu \mathrm{Bq} / \mathrm{m}^{3}$ (September 30-October 1, 2004). The average concentration of the study period was $10.54 \mu \mathrm{Bq} / \mathrm{m}^{3}$.

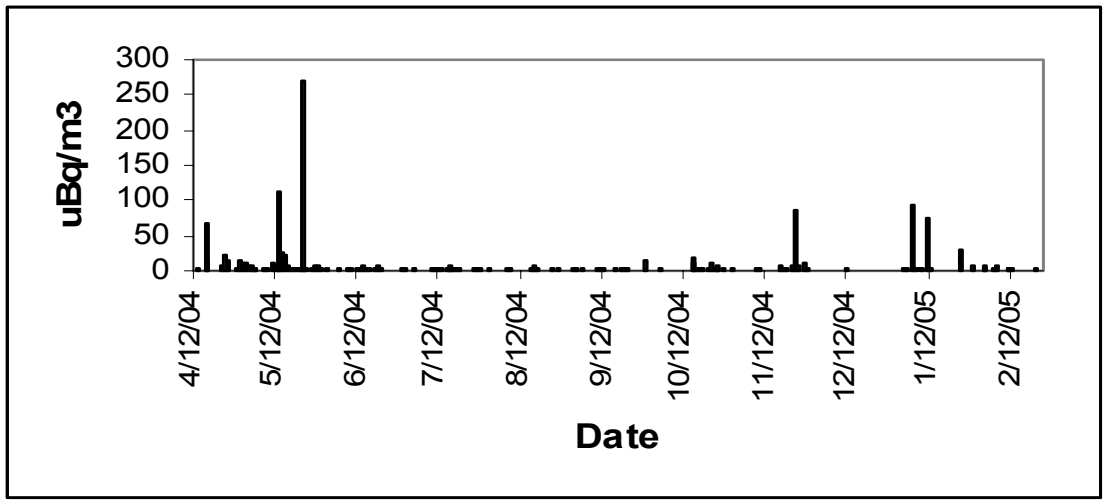

Figure 1: Cs-137 concentration trend from April 2004 to February 2005 in Kuwait. 
The monthly average Cs- 137 concentrations and days detecting Cs-137 were shown in Figures 2 and 3. It can be seen that the higher concentrations were in May $2004\left(22.3 \mu \mathrm{Bq} / \mathrm{m}^{3}\right)$ and January $2005\left(22.9 \mu \mathrm{Bq} / \mathrm{m}^{3}\right)$ although the number of the days detecting Cs-137 were not varied a lot except May 2004 and December 2004. This discovery is partially agreed with previous measurements from 1995 to 1999 [5]. It still shows that the chance of detecting Cs-137 is in the spring and summer months; but that January 2005 had the highest concentration needs to be paid more attention. May 2004 had the highest number of days ( 25 days) with detecting Cs-137, but not the highest average concentration of Cs137. Instead, January 2005 had the highest average Cs-137 concentration with only 10 days detecting Cs- 137.

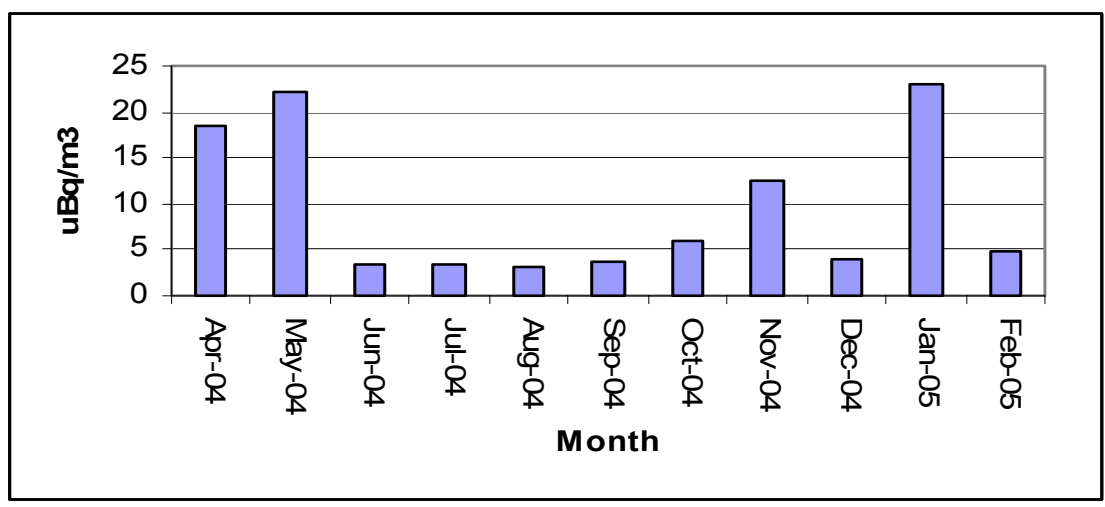

Figure 2: Monthly average Cs-137 concentrations from April 2004 to February 2005 in Kuwait.

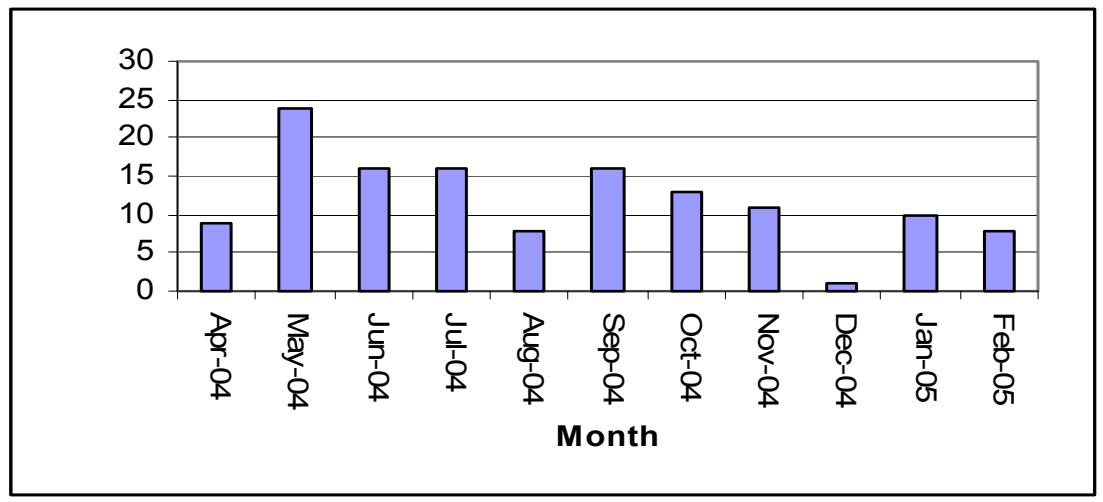

Figure 3: Monthly days detecting Cs-137 from April 2004 to February 2005 in Kuwait. 


\subsection{Comparison of Cs-137 concentrations}

Table 1 lists the Cs-137 concentrations obtained in Kuwait from 1995 - 1999 [5] and April 2004 - February 2005. It is obvious that the concentration of Cs-137 is almost the same level in the two study periods. Actually, it is not surprised to find that the two periods have the same concentration level since the half-life of Cs-137 is 30.1 years. If compared the Cs-137 concentrations obtained in Kuwait from April 2004 - February 2005 to those data obtained in other countries from 1995 - 1999 [5] and Germany from April 2004 to February 2005, the Kuwait Cs137 concentration is still the highest (Table 1).

Table 1: $\quad$ Cs-137 concentrations in different countries obtained from 1995 1999 and April 2004 - February 2005.

\begin{tabular}{|c|c|c|c|}
\hline Time and Location & Ave. $\mu \mathrm{Bq} / \mathrm{m}^{3}$ & Maximum & Minimum \\
\hline 1995 - 1999, Kuwait & 10.60 & 107.84 & 1.44 \\
\hline $1995-1999$, Buenos Aires, Argentina & 2.87 & 10.52 & 0.98 \\
\hline 1995-1999, Schauinsland, Germany & 0.75 & 17.34 & 0.12 \\
\hline April 2004 - February 2005, Sch. Ger. & 2.19 & 21.47 & 0.80 \\
\hline April 2004 - February 2005, Kuwait & 10.54 & 270.70 & 1.40 \\
\hline
\end{tabular}

\subsection{Health effect of Cs-137 in Kuwait}

As discussed in reference 5, the human health effect of Cs-137 in Kuwait is not obvious. Bielgalski et al. [5] used a multi-compartment lung model [7] to assess the health effects. The model assumes that the particles deposition in the respiratory tract is governed by the size distribution of the inhaled aerosol, and that the clearance rate of the deposited particles is governed by the deposition of the particles. If using the same calculation method as discussed in reference 5, the calculated committed dose equivalent for airborne Cs-137 from May 24-25 is listed in Table 2. In this calculation, it still assumes Cs-137 aerosol median diameter of $1 \mu \mathrm{m}$ with a geometric standard deviation of 4 , standard inhalation rate of $20 \mathrm{~m}^{3} /$ day, and exposure to this concentration for entire period. It can be seen that although a higher concentration of Cs-137 was detected in May 24-25, $2004\left(270.70 \mu \mathrm{Bq} / \mathrm{m}^{3}\right)$, the committed dose equivalent to entire body was only 4.49E-11. This number is still less than the International Commission on Radiological Protection (ICRP) annual limit (5.00E-2).

\subsection{Source apportionment of Cs-137 in Kuwait}

Until now, we still cannot positive identified the sources of the Cs-137 in Kuwait. But the following wind-roses can prove very useful information. 
Table 2: $\quad$ Committed dose equivalent for airborne Cs-137 in May 24-25, 2004 in Kuwait City, Kuwait.

\begin{tabular}{|c|c|c|c|}
\hline $\begin{array}{c}\text { Collection } \\
\text { start }\end{array}$ & $\begin{array}{c}\text { Collection } \\
\text { stop }\end{array}$ & $\begin{array}{c}\text { Atmospheric } \\
\text { activity } \\
\text { concentration, } \\
\mu \mathrm{Bq} / \mathrm{m}^{3}\end{array}$ & $\begin{array}{c}\text { Committed dose } \\
\text { equivalent to } \\
\text { entire body, Sv }\end{array}$ \\
\hline May 24, 2004 & May 25, 2004 & 270.70 & $4.49 \mathrm{E}-11$ \\
\hline $\begin{array}{c}\text { ICRP annual } \\
\text { Limit (8) }\end{array}$ & & & $5.00 \mathrm{E}-2$ \\
\hline
\end{tabular}

Figures 4-6 show the wind-roses of the days with higher Cs-137 in Kuwait. Those days were May 25-26 (270.70 $\left.\mu \mathrm{Bq} / \mathrm{m}^{3}\right)$, May 13-14 (114. .24 $\left.\mu \mathrm{Bq} / \mathrm{m}^{3}\right)$, and November $23-24\left(84.81 \mu \mathrm{Bq} / \mathrm{m}^{3}\right)$. It can be seen from the wind-roses that the dominated wind directions were from southern-west. The wind-roses were created from meteorological data collected at a well calibrated meteorological station in KISR about 100 meters west of the RASA station.

Figure 7 shows the wind-rose for June 11-12, 2004 with the lower Cs-137 concentration. This figure also shows that the dominated wind direction was also from southern west, but had many other wind directions. Generally speaking, it seems that the Cs-137 sources in Kuwait City might be from the southern west directions.

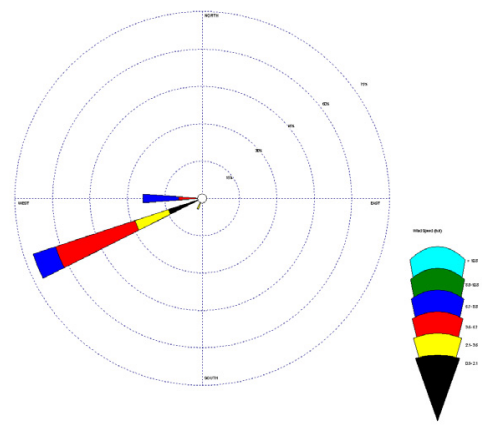

Figure 4: $\quad$ Wind-rose for Many 24-25, 2004.

The monthly wind-roses for May 2004 and August 2004 are shown in Figures 8 and 9. May 2004 had higher Cs-137 concentration compared to August 2004. From the wind-roses, it can be seen both months' dominated wind directions were from the same direction. Therefore, although the Cs-137 sources might be from the southern west, the Cs-137 concentrations can be depended on human and natural activities. For example, dust storms from the southern west directions can bring more PM10 in the atmosphere, and consequently more Cs-137. 


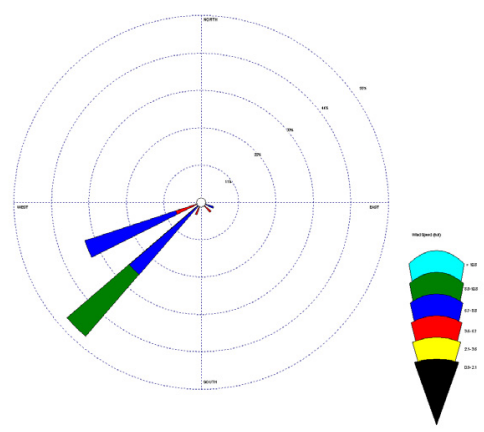

Figure 5: $\quad$ Wind-rose for May 13-14, 2004.

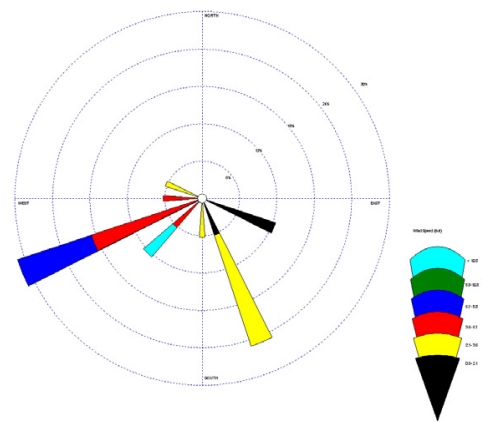

Figure 6: $\quad$ Wind-rose for November 23-24, 2004.

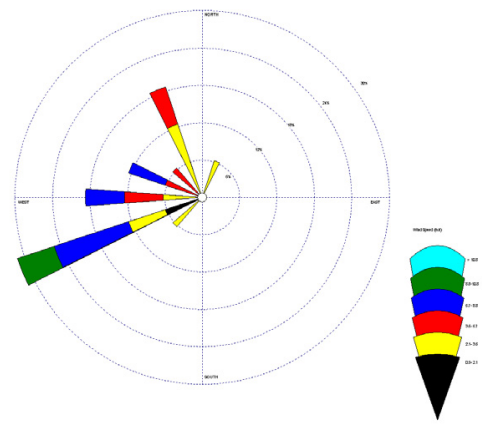

Figure 7: Wind-rose for June 11-12, 2004.

Table 3 lists Cs-137 concentration obtained in January of different years based on available information. We found that the highest average Cs-137 concentration was in January 2005 with 10 days' Cs-137 detections. It can be 
seen from Table 2 that it is not always the same trend. For example, there was no detection of Cs-137 in January in 1996 and 1997. This further indicates that many artificial and natural events can affect the concentration of Cs-137 in the atmosphere.

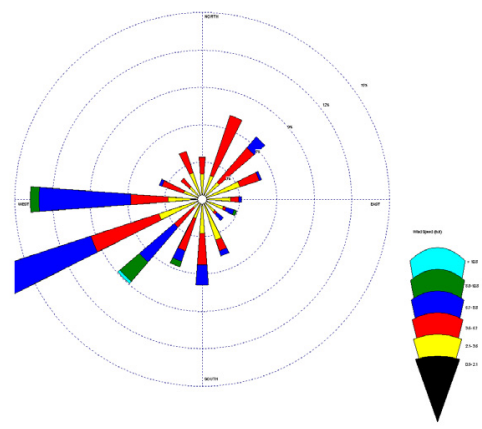

Figure 8: $\quad$ Wind-rose for May 2004.

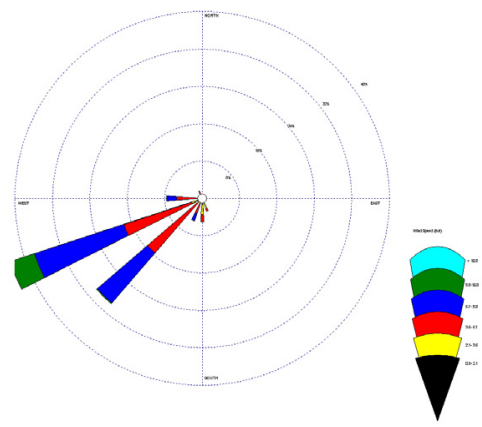

Figure 9: $\quad$ Wind-rose for August 2004.

Table 3: Comparison of detection days and concentrations of Cs-137 in January of different years.

\begin{tabular}{|l|l|l|}
\hline \multirow{2}{*}{ Year } & \multicolumn{2}{|l|}{ January Cs-137 } \\
\cline { 2 - 3 } & Detection Days & Concentration $\mu \mathrm{Bq} / \mathrm{m}^{3}$ \\
\hline 1996 & 0 & 0 \\
\hline 1997 & 0 & 0 \\
\hline 1999 & 2 & 2.77 \\
\hline 2005 & 10 & 22.90 \\
\hline
\end{tabular}




\section{Conclusions}

Many artificial and natural radionuclide elements have been measured in the Kuwait City RASA station. The average Cs-137 concentrations in the PM10 of the atmosphere in Kuwait City, Kuwait have been the highest for several years. This trend might be last for many more years. Although the Cs-137 concentrations in Kuwait will not affect human health, it is still worth to find the sources. This study indicates the higher chance to detect Cs-137 is not only in spring and summer, but winter is also included. The data collected from a nearby meteorological station indicates that the Cs-137 sources might from southernwest side. More attentions need to be paid to this direction.

\section{Acknowledgements}

The authors want to thank support from Kuwait Institute for Scientific Research (KISR), CTBTO and many individuals from Costal and Air Pollution Department, Environment and Urban Development Division of KISR.

\section{References}

[1] Holmes, C.W., Short-Lived Isotopic Chronometers- A Means of Measuring Decadal Sedimentary Dynamics, U.S. Geological Survey, Department of the Interior, Fact Sheet FS-073-98, 1998.

[2] Singhal, R.K., Estimation of Deposition Velocities for 85Sr, 131I, 137Cs on Spinach Radish and Beans Leaves in a Tropical Region under Simulated Fallout, Water, Air, \& Soil Pollution, 158(1-4), pp181-193, 2004.

[3] Ebert, D., Hoerner, J., Kang, C., White, B., Biegalski, S. \& Massari, J., Treansactions of American Nuclear Society 1990 Summer Meeting, San Diego, CA, June 1999.

[4] Eriksson, M., Distribution and Flux of 238Pu, 239, 240Pu, $241 \mathrm{Am}$, $137 \mathrm{Cs}$ and $210 \mathrm{~Pb}$ to High Arctic Lakes in the Thule District (Greenland), Journal of Environmental Radioactivity, 75(3), pp285-300, 2004.

[5] Biegalski, S.R., Hosticka, B. and Mason, L.R., Cesium-137 concentrations, Trends, and Sources Observed in Kuwait City, Kuwait, Journal of Radioanalytical and Nuclear Chemistry, 248(3), pp643-649, 2001.

[6] General Dynamics, RASA Users Manual, Veridian Systems Division, USA, 2003.

[7] Cember, H., Introduction to Health Physics, Mc-Graw-Hill, Inc., New York, 1983.

[8] International Commission on Radiological Protection (ICRP), ICRP Publication 30, Part I, 5(1-6), 1981. 